\title{
Yannick Séité, Du livre au lire. «La Nouvelle Héloïse» roman des Lumières
}

\section{Paola Sosso}

\section{Q OpenEdition}

1 Journals

\section{Edizione digitale}

URL: https://journals.openedition.org/studifrancesi/40767

DOI: 10.4000/studifrancesi.40767

ISSN: 2421-5856

\section{Editore}

Rosenberg \& Sellier

\section{Edizione cartacea}

Data di pubblicazione: 1 juillet 2004

Paginazione: 198

ISSN: 0039-2944

\section{Notizia bibliografica digitale}

Paola Sosso, «Yannick Séité, Du livre au lire. «La Nouvelle Hélö̈se» roman des Lumières», Studi Francesi

[Online], 142 (XLVIII | I) | 2004, online dal 30 novembre 2015, consultato il 09 septembre 2021. URL: http://journals.openedition.org/studifrancesi/40767; DOI: https://doi.org/10.4000/studifrancesi. 40767

Questo documento è stato generato automaticamente il 9 septembre 2021.

\section{(c)}

Studi Francesi è distribuita con Licenza Creative Commons Attribuzione - Non commerciale - Non opere derivate 4.0 Internazionale. 


\title{
Yannick Séité, Du livre au lire. «La Nouvelle Héloïse» roman des Lumières
}

\author{
Paola Sosso
}

\section{NOTIZIA}

YANNICK SÉITÉ, Du livre au lire. «La Nouvelle Héloïse» roman des Lumières, Paris, Champion, 2002 («Les dix-huitièmes siècles»), pp. 575.

1 Il volume si apre con un'introduzione di carattere metodologico in cui l'autore chiarisce la sua posizione di «dette et de débat» nei confronti di Gérard Genette e di Roger Chartier. Alla frontiera tra storia del libro, storia e teoria della lettura e della critica testuale, il testo si situa alla confluenza tra diverse discipline nel tentativo, certamente originale, di leggere la Julie partendo, per così dire, da elementi apparentemente marginali: elementi tipografici, prefazioni, note, frontespizio, tutto ciò che, in definitiva, costituisce il paratesto. L'autore analizza innanzitutto l'edizione di base pubblicata da Rey nel 1761, ma per alcuni elementi si affida anche ad edizioni posteriori, limitandosi pero alle versioni che Rousseau potè visionare e controllare durante la sua vita. Chiaro e riassuntivo, viene presentato nelle prime pagine del volume uno schema degli elementi péritextuels che vengono presi in esame: a questo primo tableau fa seguito, nelle pagine successive, una sintesi dei dati épitextuels, utile per rendere evidenti al lettore gli elementi oggetto di analisi. Lo studio procede prendendo in esame gli elementi paratestuali nell'ordine in cui un lettore del tempo li avrebbe potuti scoprire, ammettendo da parte sua una stretta vigilanza: secondo la loro apparizione in ordine cronologico (per ciò che concerne l'épitexte) o fisico (per il péritexte). Si tratta quasi di una rilettura fittizia del testo, che garantisce tuttavia una coerenza interna allo studio. Una prima parte del volume («Le livre avant le livre», pp. 49-108) ripercorre le circostanze della pubblicazione de La Nouvelle Héloïse mettendo in luce gli elementi dell'épitexte, tutti quegli elementi ciòè del paratesto non materialmente allegati al testo, ma «n'importe où hors du livre»: lettere, altri testi di Rousseau, stampe... Accanto a un épitexte "privato», vi sono anche un insieme di scritti e 
di elementi che pertengono alla sfera pubblica, il cui rapporto con il romanzo appare evidente. La lettre à d'Alembert, innanzitutto, il cui rapporto con la Julie viene ben evidenziato dall'autore, e alcune forme di «pubblicità» che anticiparono l'uscita del romanzo: lo studio di questi elementi mette in luce un insieme di relazioni che definiscono un mondo poco studiato e poco noto ai rousseauisti, contribuendo a ricreare le circostanze in cui prese forma e si costruì il successo de La Nouvelle Héloïse. La seconda parte del volume («Abords: du péritexte éditorial au péritexte auctorial», pp. 109-205) si concentra sull'analisi di elementi testuali o materiali compresi all'interno del libro, cercando di valutare l'impatto sulla lettura di questi elementi «marginali» (formato, carta, elementi tipografici, titoli) che costituiscono «luoghi di passaggio, di cesura tra la realtà e la finzione» (péritexte matériel). L'analisi si sposta poi verso gli elementi peritestuali situati nel cuore stesso del romanzo: nella terza parte («Les préfaces et les notes», pp. 207-350), l'autore analizza alcuni scritti fondamentali, note e prefazioni, in cui le riflessioni sul romanzo come genere e sulla lettura appaiono di estremo interesse. Si tratta di testi ingiustamente dimenticati o messi ai margini, che occorre invece recuperare e non solo nella loro dimensione teorica, perché la lettura è inscritta anche nel paratesto.

2 La disamina che offre questo terzo volet apre certamente nuove prospettive agli studiosi di Rousseau: il lettore si trova dinanzi a un nuovo punto di vista, un nuovo genere di analisi che include a pieno titolo al suo interno testi spesso lasciati in sordina il cui contenuto è invece parte integrante del romanzo. Lo studioso distingue e classifica $\mathrm{i}$ diversi elementi, le due prefazioni e i vari tipi di note, con l'intento di far risaltare la portata e il valore del loro contenuto, ascrivibile, a seconda dei casi, alla storia della lettura, alla riflessione sul genere romanzo, sulla scrittura, sulla morale... A una ricezione «tradizionale» della Julie, chiarisce l'Autore nell'ultima parte del suo studio («Rousseau et ses deux lectures», pp. 351-445), centrata su una lettura «effusive et sentimentale», corroborata dalle inchieste sui lettori condotte da Claude Labrosse e Robert Darnton, si affianca in realtà un secondo tipo di lettura. Se tante lettere testimoniano l'accoglienza per così dire «sentimentale» del romanzo, occorre tuttavia sottolineare che Rousseau, attraverso il paratesto, ha cercato di indurre il lettore a una lettura basata sulla distanza e la riflessione. Jean-Jacques ha partecipato, anche se in misura minore rispetto ad alcuni suoi contemporanei, all'elaborazione di quello che l'Autore chiama «le livre des Lumières», e a una concezione della lettura che ad esso si collega, in cui non è per nulla netta la frontiera tra lettura filosofica e lettura letteraria. Leggere è per Rousseau, come egli stesso afferma in Idée de la méthode dans la composition d'un livre, creare dei collegamenti, lavorare sul testo e lasciarsi influenzare da esso secondo il principio di una lecture éclairée. «Il faut laisser quelque chose à deviner au lecteur», scrive Rousseau in una nota della quinta parte del romanzo, preconizzando un ruolo del lettore attivo che non esclude, ma si affianca, a un lettore affascinato dall'aspetto più prettamente sentimentale del testo. Il lettore attento, partecipe, deve lavorare sulle parti nascoste o dimenticate del libro, includere nella sua analisi tutti i dati forniti dal paratesto, secondo un metodo oggi diffuso che affonda le sue radici nel Settecento. Una storia letteraria del libro, scrive in conclusione lo studioso, deve necessariamente porre al centro della sua analisi la figura dello scrittore, il suo stile, il suo modo di concepire l'oggetto-libro e la lettura. Chiude il volume un'edizione critica delle note della Julie presentate sotto forma di fiches e una ricca bibliografia che include: studi sul paratesto e la storia del libro, lavori teorici e di storia della lettura e volumi di critica rousseauista riferita agli argomenti sopracitati. 